https://doi.org/10.30910/turkjans.679896

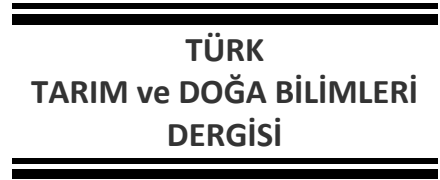

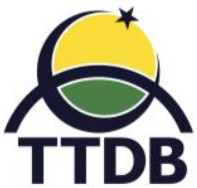

www.dergipark.gov.tr/turkjans

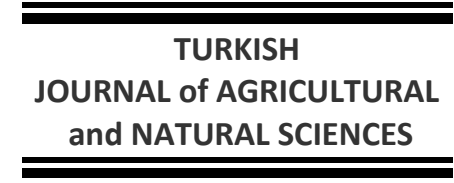

Araştırma Makalesi

\title{
Ardahan Yöresinde Yetişen Kılıç Otu Bitkisinin (Hypericum perforatum) Antimikrobiyal ve Antioksidan Etkilerinin Araştırılması
}

\author{
Vesile DÜZGÜNER*, Nurcan ERBIL \\ Ardahan Üniversitesi, Sağlık Bilimleri Fakültesi, Hemşirelik Bölümü, 75000, Ardahan
}

*Sorumlu yazar: vesileduzguner@ardahan.edu.tr

\section{Özet}

Dünyanın birçok yerinde bulunan Hypericum perforatum ülkemizde "kılıç otu" ya da "sarı kantaron" olarak bilinmektedir. Türkiye'nin iklimi kılıç otu için oldukça uygundur. Astım, mide ülseri, midede asit fazlalığı, akciğer hastalıkları, damar sertliği ve sinir iltihaplarında da faydalı olduğu bilinmektedir. Bu çalışmada Ardahan yöresinden toplanan ve Hypericaceae familyasına ait olan kılıç otunun antioksidan ve antimikrobiyal aktiviteleri incelenmiştir. Kurutulmuş bitki numunesi ethanol ve metanol ile ekstrakte edilmiştir. Kılıç otu ethanol ve metanol ekstraktlarının antimikrobiyal aktivitesi Pseudomonas aeruginosa (ATCC 9027), Staphylococcus aureus (ATCC 6538), Bacillus megaterium, Escherichia coli, Yarrovia lipolytica, Candida albicans ve Saccharomyces cerevisiae'ya karşı test edilmiştir. Bitkilerin hayati mekanizmalarına katılan glutatyon (GSH) düzeyi spektrofotometrik olarak, toplam antioksidan kapasiteleri (TAK) ise ELISA yöntemi ile ölçülmüştür. Analizler sonucunda kılıç otu metanol ekstraktında etanol ekstraktına oranla daha yüksek antibakteriyel aktiviteye rastlanırken, her iki ekstraktta da antifungal etki gözlenmemiştir. Örnekler GSH düzeyi bakımından çözücülere göre farklılık göstermiştir. Toplam antioksidan kapasite ölçümlerinde ise anlamlı sonuçlar elde edilmiştir.

Anahtar kelimeler: Antimikrobiyal, antioksidan, kılıç otu, Hypericum perforatum, glutatyon.

\section{Investigation of Antimicrobial and Antioxidant Effects of Kılıç Otu Plant (Hypericum perforatum) in Ardahan Region}

\begin{abstract}
Hypericum perforatum, which is found in many parts of the world, is known as "kılıc otu" or "sarı kantaron" in our country. The climate of Turkey is the most suitable climate for kılıç otu. It is known to be beneficial in asthma, stomach ulcer, excess acid, lung diseases, and arteriosclerosis and nerve inflammation. In this study the antimicrobial activities and antioxidant capacity of kılıç otu samples which belongs to Hypericaceae family was investigated. The dried plant samples were extracted with ethanol and methanol. Methanol and ethanol extracts of kılıç otu was tested for antimicrobial activity against Pseudomonas aeruginosa (ATCC 9027), Staphylococcus aureus (ATCC 6538), Bacillus megaterium, Escherichia coli, Yarrovia lipolytica, Candida albicans and Saccharomyces cerevisiae. The measurements of glutathione (GSH) levels which participate in vital mechanism of plants were done spectrophometrically and total antioxidant capacity (TAC) was done by ELISA method. The methanolic extract of kılıç otu exhibited higher antibacterial activity than ethanolic extract, but both extracts did not display antifungal effect. GSH levels are various in different solvents. The results showed that the all the studied species have significant results of total antioxidant capacity.
\end{abstract}

Key words: Antimicrobial, antioxidant, kılıç otu, Hypericum perforatum, glutathione.

Giriş

Son yıllarda tıbbi bitkilerde bulunan doğal antioksidanlara ve bitki antimikrobiyallerine olan ilgi oldukça artmıştır. Bunun başlıca nedenleri arasında patojen mikroorganizmaların antibiyotiklere karşı direnç geliştirmesi, 
antibiyotiklerin istenmeyen yan etkilere sahip olabilmesi ve oksidatif stresin kanser ve diyabet gibi birçok hastalığın epidemiyolojisinde rol aldığının tespit edilmesidir.

Hypericum perforatum L. (St. John's Wort, SJW), uzun bir farmasötik uygulama geçmişi olan, dünyada yaklaşık 450 tür ile dağılım gösteren geleneksel, çok yıllık bir tıbbi bitkidir (Altun ve ark., 2013). Hypericum cinsi Türkiye florasında 89 türle temsil edilmektedir (Davis ve Cullen, 1984). Anadolu'da sarı kantaron, binbirdelik otu, kılıç otu, kanotu, mayasıl otu gibi birçok yerel isimle bilinmektedir (Altun ve ark., 2013). John's Wort'un çiçekli bölümlerinin zeytinyağı özütü depresyon, peptik ülserler, kesikler, yanıklar, dispepsi, karın ağrıları, bakteriyel enfeksiyonlar, migren baş ağrıları ve siyatik ağrısına karşı kullanılan popüler bir halk ilacıdır (Süntar ve ark., 2010). Kılıç otunun antidepresan, antienflamatuar, antiepileptik, analjezik ve yara iyileşmesi etkileri olduğu bildirilmiştir (Dost ve ark., 2009). Günümüzde, hidro-alkolik ekstrelere dayanan formülasyonların yanı sıra lipofilik SJW preparatları, cilt ve deri altı doku bozukluklarının küçük inflamasyonlarının semptomatik tedavisinde de kullanılmaktadır (Heinrich ve ark., 2017).

Reaktif oksijen türleri (ROS) normalde aerobik hücrelerin metabolizmasında meydana gelen birçok redoks işlemi ile üretilir. Bu türler oldukça reaktif ve hücrelere zararlıdır. Yok edilmezlerse proteinler, DNA ve lipidler gibi önemli moleküllere zarar verebilirler. Hücreler, ROS'un zarar verici etkilerini önlemeye yardımcı olan antioksidan enzimler ve nonenzimatik bileşikler de dahil olmak üzere birçok savunma mekanizmasını barındırmaktadır (Silva ve ark., 2005). Oksidatif stres, Alzheimer hastalığı (Behl ve Mosmann, 2002) gibi nörodegradatif bozuklukların gelişiminde önemli bir rol oynayabildiği gibi; kanser, arteriyoskleroz ve romatizma gibi kronik hastalıkların gelişiminde de etkilidir (Halliwell, 1999). Yapılan çalışmalar Hypericum perforatum bitkisinin zengin flavonois içeriğe sahip olduğunu ve antioksidan etkinliğinin serbest radikalleri temizleme, metal şelatı ve serbest radikalleri baskılama şeklinde olabileceğini bildirmişlerdir (EI Sherbiny ve ark., 2003; Zou ve ark., 2004).

Oksidatif hasarı önlemeye yardımcı olabilecek tıbbi ve diyet bitkilerinde bulunan fenoller, yani doğal antioksidanlara ilgi artmaktadır (Zheng ve Wang, 2001). Artan serbest radikal oluşum durumlarında, diyet antioksidanlarının alımı yoluyla endojen antioksidanların takviyesi, oksidatif olarak hasar görmüş moleküllerin kümülatif etkilerinin azaltılmasında özel önem taşıyabilir (Rahiman ve ark., 2013).
$\mathrm{Bu}$ bilgiler ışığında çalışmada Ardahan yöresinde yetişen ve halk arasında sıklıkla kullanılan kılıç otu bitkisinin antimikrobiyal ve antioksidan etkinliğinin belirlenmesi amaçlanmıştır.

\section{Materyal ve Yöntem}

Kılıç otu örnekleri, Haziran 2017'de Ardahan ili Posof ilçesi Türkgözü köyünün Gürcistan sınırına yakın bölgesinden (Rakım: 1218 m) toplanmıştır. Toz ve toprak kalıntılarından arındırılan bitki örnekleri oda sıcaklığında gölgede kurutulmuş ve mutfak tipi öğütücü yardımıyla toz haline getirilmiştir.

\section{Ekstraktların hazırlanması}

Toz halinde getirilmiş olan bitki örneğinden 10'ar g tartılmış ve üzerlerine ayrı ayrı $300 \mathrm{ml}$ metanol (pi: 6.6) ve $300 \mathrm{ml}$ etanol (pi: 5.2) eklenerek 8 saat boyunca Soxhlet sistemi aracılığıyla ekstrakte edilmiştir. Elde edilen ekstrakt, rotary evaporatör (SciLogex RE100-Pro) ile konsantre edilmiştir. Elde edilen ekstraktlar steril mikrofiltre $(0.2 \mu \mathrm{m}$ gözenek çaplı, Sartorius Minisart ${ }^{\circledR}$ Syringe Filter) ile sterilize edilmiş ve kullanıma kadar $-20^{\circ} \mathrm{C}$ 'de muhafaza edilmiştir.

\section{Antimikrobiyal aktivitenin belirlenmesi}

Antimikrobiyal aktivite analizlerinde kılıç otuna ait etanol ekstraktı için disk difüzyon metodu kullanılırken, metanol ekstraktı için agar kuyu difüzyon yöntemi kullanılmıştır (Collins ve ark., 1989). Test mikroorganizması olarak Pseudomonas aeruginosa ATCC 9027, Escherichia coli, Bacillus megaterium, Staphylococcus aureus ATCC 6538, Yarrovia lipolytica, Candida albicans ve Saccharomyces cerevisiae kullanılmıştır. Test maddesi olarak herbir ekstrakttan 100'er $\mu \mathrm{l}$ kullanılmıştır. Pozitif kontrol olarak ise Ampicillin disk kullanılmıştır. Petriler $37^{\circ} \mathrm{C}$ 'de 48 saat inkübe edilmiş ve oluşan inhibisyon zonları dijital kumpas ile ve $\mathrm{mm}$ olarak ölçülmüştür. Analizler üç tekrarlı olarak gerçekleştirilmiş ve ortalama değerleri kullanılmıştır.

\section{Biyokimyasal analizler}

Glutatyon (GSH) düzeyleri spektrofotometrik yöntemle ölçülmüştür (Sedlak ve Lindsay, 1968). 5,5-dithiobis-2-nitrobenzoic asit ile örneklerdeki GSH'ın reaksiyonu ile oluşan son ürün 410 nm'de spektrofotometrik olarak okunmuş ve sonuçlar $\mathrm{mmol} / \mathrm{l}$ olarak ifade edilmiştir.

Toplam antioksidan kapasite (TAC) ticari ELISA kiti ile belirlenmiştir. Analiz, ABTS ${ }^{{ }^{\prime}}$ ye $\left(2,2^{\prime}-\right.$ Azino-di- [3-etilbenztiazolin sülfonat]), bir peroksidaz (metmyoglobin) ve $\mathrm{H}_{2} \mathrm{O}_{2}$ ile radikal katyon $\mathrm{ABTS}^{\oplus+1} \mathrm{yı}$ üretmek üzere inkübe edilir. $\mathrm{Bu}$, 600 nm'de ölçülen nispeten sabit mavi-yeşil bir 
renge sahiptir. Eklenen numunedeki antioksidanlar, bu renk üretiminin konsantrasyonları ile orantılı bir dereceye kadar bastırılmasına neden olur.

Ekstraktların toplam oksidan kapasitesini (TOC) ölçmek için ticari ELISA kiti kullanılmıştır. Numunede bulunan oksidantlar demir iyonukenetleme kompleksini ferrik iyona okside eder. Oksidasyon reaksiyonu, reaksiyon ortamında bol miktarda bulunan güçlendirici moleküller tarafından uzatılır. Demir iyonu asidik bir ortamda kromojen ile renkli bir kompleks yapar. Renk dansitesi, örneklerde bulunan toplam oksidan molekül miktarı ile ilgilidir.

Numunelerin fenolik içeriği, Lister ve Wilson (2001) tarafından önerilen yöntem kullanılarak Folin-Ciocalteu reaktifi ile tespit edilmiştir. Bitki ekstraktı $(100 \mu \mathrm{l}) 0.2 \mathrm{ml}$ Folin-Ciocalteu reaktifi ve $2 \mathrm{ml} \mathrm{H}_{2} \mathrm{O}$ ile karıştırılmış ve 3 dakika oda sıcaklığında inkübe edilmiştir. Karışıma $1 \mathrm{ml} \% 20$ sodyum karbonat eklendikten sonra, oda sıcaklığında 1 saat inkübasyondan sonra toplam polifenoller belirlenmiştir. Elde edilen mavi rengin absorbansı spektrofotometrik olarak $765 \mathrm{~nm}$ 'de ölçülmüştür. Kuantifikasyon, standart gallik asit eğrisine göre yapılmıştır. Bütün tespitler üç tekrar halinde gerçekleştirilmiştir $(n=3)$.

\section{istatistik}

İstatistiksel analizler SPSS (versiyon 25) programında yapılmıştır. Sonuçlar "ortalama \pm SD" olarak sunulmuş olup, $\mathrm{p}<0.05$ değeri anlamlı kabul edilmiştir.

\section{Bulgular ve Tartışma}

Kılıç otundan elde edilen etanol ve metanol ekstraklarında belirlenen toplam antioksidan ve oksidan kapasite düzeyleri Çizelge 1'de gösterilmiştir. Metanol ekstraktında belirlenen toplam antioksidan kapasite etanol ekstraktına göre daha yüksek belirlenirken, bu durumun tam tersi olarak daha düşük bir toplam oksidan kapasite değeri tespit edilmiştir. Bu nedenle kılıç otu metanol ekstraktının oksidatif stres indeksi daha düşük çıkmıştır.

Çizelge 1. Kılıç Otunun Toplam Oksidan ve Antioksidan Kapasite Değerleri.

\begin{tabular}{lcc}
\hline & Etanol Ekstraktı & Metanol Ekstraktı \\
\hline Toplam Antioksidan Kapasite $(\mu \mathrm{mol} / \mathrm{L})$ & $4330 \pm 0.0021$ & $5460 \pm 0.0016$ \\
Toplam Oksidan Kapasite $(\mu \mathrm{mol} / \mathrm{L})$ & $15.56 \pm 0.07$ & $14.46 \pm 0.05$ \\
Oksidatif Stres Indeksi $(\mu \mathrm{mol} / \mathrm{L})$ & $0.359 \pm 0.003$ & $0.264 \pm 0.009$ \\
\hline Çizelge 2'de görüldüğü üzere, metanol & metanol ekstratının toplam fenolik içeriğinin \\
ekstraktında etanol ekstraktlarına göre daha & $(1639.66 \pm 22.73)$ etanol ekstraktına oranla (470.33 \\
yüksek oranda GSH içeriği saptanmıştır (sırasıyla, & $\pm 24.83)$ yaklaşık 4 kat daha fazla olduğu \\
$470.97 \mathrm{mmol} / \mathrm{l}, 417.41 \mathrm{mmol} / \mathrm{l}, \mathrm{p}<0.05)$. Ayrıca; & görülmektedir (p<0.001).
\end{tabular}

Çizelge 2. Kılıç Otunun GSH ve Toplam Fenolik İçerik Düzeyleri.

\begin{tabular}{llc}
\hline & Etanol Ekstraktı & Metanol Ekstraktı \\
\hline GSH (mmol/L) & $417.41 \pm 1.78$ & $470.97 \pm 9.91$ \\
Toplam Fenolik İçerik (mGAE/g dw) & $470.33 \pm 24.83$ & $1639.66 \pm 22.73$ \\
\hline Çalışmadan elde edilen antimikrobiyal & aeruginosa ATCC 9027'ya karşı antibakteriyel \\
aktivite sonuçları incelendiğinde (Tablo 3) ise kılıç & aktivite gösterdiği tespit edilmiştir. Öte yandan, \\
otu metanol ekstraktının tüm test bakterileri & metanol ve etanol ekstraktlarının her ikisinin de \\
üzerinde değişen oranlarda etki gösterdiği tespit & test mikroorganizmaları üzerinde antifungal \\
edilirken, etanol ekstraktının kullanılan test & aktivite sergilemediği belirlenmiştir. \\
mikroorganizmalarından sadece Pseudomonas &
\end{tabular}

Çizelge 3. Kılıç Otunun Antimikrobiyal Aktivitesi.

\begin{tabular}{lccc}
\multicolumn{1}{c}{ Bakteri } & $\begin{array}{c}\text { Etanol Estraktı } \\
\text { (mm) }\end{array}$ & $\begin{array}{c}\text { Metanol Estraktı } \\
\text { (mm) }\end{array}$ & $\begin{array}{c}\text { Ampicillin } \\
\text { (mm) }\end{array}$ \\
\hline Staphylococcus aureus ATCC 6538 & - & $23.31 \pm 0.51$ & $10.10 \pm 0.61$ \\
Bacillus megaterium & - & $18.07 \pm 0.11$ & $9.58 \pm 0.41$ \\
Escherichia coli & - & $20.46 \pm 0.78$ & $9.30 \pm 0.48$ \\
Pseudomonas aeruginosa ATCC 9027 & $13.28 \pm 2.69$ & $19.77 \pm 1.07$ & $11.71 \pm 0.97$ \\
Yarrovia lipolytica & - & - & - \\
Candida albicans & - & - & - \\
Saccharomyces cerevisiae & - & - & - \\
\hline
\end{tabular}


Çalışmamız Ardahan yöresinde yetişen kılıç otu bitkisinin antimikrobiyal ve antioksidatif etkileri üzerine odaklanmaktadır. Alt türler, habitat ve büyüme koşulları gibi çeşitli faktörler kimyasal bileşim üzerinde önemli bir etkiye sahip olabilmektedir. Nitekim, bazı çalışmalar morfolojik karakterlerin değişkenliğini, çeşitli alt türlerin ortaya çıkmasına neden olduğunu ve aynı zamanda sınırlı alanlarda bulunan popülasyonlardaki kompozisyondaki değişiklikleri bildirmiştir (Marelli ve ark., 2014). H. perforatum özütlerinin fenolik içeriğinin yüksek olmasından dolayı antioksidan aktivitesinin fazla olduğu düşünülmektedir. Ancak bu antioksidan aktivitesinden hangi fenolik içerik sınıfının sorumlu olduğu tam olarak saptanamamıştır (Orsic ve ark., 2011).

Çalışmamızda metanolik ve etanolik ekstraktlarda yüksek düzeyde antioksidan kapasite ve toplam fenolik içerik tespit edilmiştir. Ancak Italya'da Hypericum spp. türlerinde antioksidan/antiradikal aktivite için yapılan taramalarda, test edilen tüm metanol-aseton ekstraktlarının, hafif ile orta dereceli bir antioksidan aktivite sergileyen farmakolojik olarak önemli bileşikler içerdiği saptanmıştır (Sagratini ve ark., 2008).

Hypericum perforatum'un antioksidan aktivitesini değerlendiren bir çalışmada, SJW özütlerinin, feokromositoma hücre hattında $\mathrm{H}_{2} \mathrm{O}_{2}$ kaynaklı oksidatif hasarı inhibe ettiğini göstermiştir. Ayrıca, $\mathrm{Fe}^{2}$ /askorbat kaynaklı sıçan beyin korteksi mitokondrisindeki lipid peroksidasyonunu da engellediği saptanmıştır (Benedi ve ark., 2004). Rotenon ile tedavi edilen sıçan beyni homojenatları üzerinde standartlaştırılmış SJW (4 mg/kg, i.p.) uygulanan başka bir çalışma, oksidatif stres kaynaklı nörodejenerasyon yaşayan yaşlı hastaların tedavisinde kullanılmasını önermiştir (SánchezReus ve ark., 2007).

Karşılaştırmalı bir çalışmada SJW, sentetik antioksidanlardan daha iyi antioksidan etki gösterdiğini ortaya koymuştur. Etanolik SJW'nin analizi, antioksidan aktivitenin genellikle flavonoidler ve fenolik asitlere atfedilmesine karşın, hiperisin ve hiperforinin de aynı şekilde etkiye sahip olduğunu ortaya koymaktadır (Orcic ve ark., 2011; Silva ve ark., 2005).

Hypericum türlerinin, E vitamini benzeri bir antioksidan aktivitesi gösterdiği ve standartlaştırılmış Hypericum perforatum ekstresinin, serbest radikal ve lipit peroksidasyonunu inhibe ettiği bildirilmektedir (Dost ve ark., 2009).

Çalışmamızda kılıç otu etanol ekstraktının test mikroorganizmalarından sadece Pseudomonas aeruginosa ATCC 9027'ya karşı antibakteriyal aktivite sergilediği, buna karşın metanol ekstraktının tüm test bakterilerine karşı aktibakteriyel etki gösterdiği gözlenmiştir. Ancak; her iki ekstraktta da antifungal aktivite tespit edilememiştir. Orhan ve ark. (2013) tarafından yapılan çalışma da kılıç otunun antibakteriyel aktiviteye sahip olduğunu ortaya koymaktadır. Ayrıca; farklı çalışmalar da kılıç otunun lipofilik SJW ekstrelerinin yara iyileştirme etkilerini (Lavagna ve ark., 2001; Orhan ve ark., 2006; Süntar ve ark., 2010) ortaya koymuştur.

\section{Sonuç ve Öneriler}

Sonuç olarak kılıç otu ekstraktlarında test bakterilerine değişen oranlarda antibakteriyel aktivite tespit edilirken, iyi seviyede antioksidan etki belirlenmiştir. Bu durum ise kılıç otunun halk arasında tıbbi amaçlı kullanımı düşünüldüğünde, sağlık destekleyici olarak değerlendirilebilmektedir.

\section{Kaynaklar}

Altun, M.L., Sever Yılmaz, B., Erdogan Orhan, I., Saltan Citoglu, G. 2013. Assessment of cholinesterase and tyrosinase inhibitory and antioxidant effects of Hypericum perforatum L. (St. John's wort). Industrial Crops and Products, 43: 87-92.

Behl, C., Mosmann, B. 2002. Antioxidant neuroprotection in Alzheimer's disease as preventive and therapeutic approach. Free Radical Biology and Medicine, 33: 182-191.

Benedí , J., Arroyo, R., Romero, C., Martín-Aragón, S., Villar A.M. 2004. Antioxidant properties and protective effects of a standardized extract of Hypericum perforatum on hydrogen peroxide-induced oxidative damage in PC12 cells. Life Science Journal, 75(10): 1263-76.

Collins, C.M., Lyne, P.M., Grange, J.M. 1989. Antimicrobial sensitivity and assay tests. Collins and Lyne's Microbiological Methods. Butterworths, London.

Davis, P.H., Cullen, J. 1984. Hypericaceae. In: Davis, P.H. (Ed.), Flora of Turkey and the East Aegean Islands, vol. 10. Edinburgh University Press, Edinburgh, pp. 96-103.

Dost, T., Ozkayran, H., Gokalp, F., Yenisey, C., Birincioğlu M. 2009. The Effect of Hypericum perforatum (St. John's Wort) on Experimental Colitis in Rat. Digestive Diseases and Sciences, 54:1214-1221.

El-Sherbiny, D.A., Khalifa, A.E., Attia, A.S., Eldenshary, E.E.D.S. 2003. Hypericum perforatum extract demonstrates antioxidant properties against elevated rat brain oxidative status induced by amnestic dose of scopolamine. Pharmacology 
Biochemistry and Behavior, 76(3-4): 525533.

Halliwell, B. 1999. Establishing the significance and optimal intake of dietary antioxidants: the biomarker concept. Nutrition Reviews, 57: 104-113.

Heinrich, M., Vikuk, V., Daniels, R., Stintzing, F.C. 2017. Characterization of Hypericum perforatum L. (St. John's wort) macerates prepared with different fatty oils upon processing and storage. Phytochemistry, Letters 20: 470-480.

Lavagna, S.M., Secci, D., Chimenti, P., Bonsignore, L., Ottaviani, A., Bizzarri, B. 2001. Efficacy of Hypericum and Calendula oils in the epithelial reconstruction of surgical wounds in childbirth with caesarean section. Farmaco, 56: 451-453.

Lister, E., Wilson, P. 2001. Measurement of Total Phenolics and ABTS Assay for Antioxidant Activity (personel communication). Crop Research Institute Lincoln, New Zealand.

Marelli, M., Conforti, F., Toniolo, C., Nicoletti, M., Statti, G., Menichini, F. 2014. Hypericum perforatum : Influences of the habitat on chemical composition, photo-induced cytotoxicity, and antiradical activity. Pharmacological Biology, 52(7): 909-918.

Orcic, D.Z., Mimika-Dukic, N.M., Franciskovic, M.M., Petrovic, S.S., Jovin, E.D. 2011. Antioxidant activity relationship of phenolic compounds in Hypericum perforatum $\mathrm{L}$. Chemistry Central Journal, 5: 34-42.

Orhan, G., Orhan, I., Sener, B. 2006. Recent developments in natural and synthetic drug research for Alzheimer's disease. Letters in Drug Design and Discovery, 3: 268-274.

Orhan, I.E., Kartal, M., Gülpinar, A.R., Cos, P., Matheeussen, A., Maes, L., Tasdemir, D., 2013. Assessment of antimicrobial and antiprotozoal activity of the olive oil macerate samples of Hypericum perforatum and their LC-DAD-MS analyses. Food Chemistry, 138: 870-875.

Rahiman, S., Tantry, B.A., Kumar, A. 2013. Variation of Antioxidant Activity and Phenolic Content of Some Common Home Remedies with Storage Time. African Journal of Traditional Complementary and Alternative Medicines, 10(1): 124-127.

Sagratini, G., Ricciutelli, M., Vittori, S., Öztürk, N., Öztürk, Y., Maggi, Y. 2008. Phytochemical and antioxidant analysis of eight Hypericum taxa from Central Italy Fitoterapia, 79: 210213.

Sánchez-Reus, M.I., Gómez del Rio, M.A., Iglesias, I., Elorza, M., Slowing, K., Benedí, J. 2007.
Standardized Hypericum perforatum reduces oxidative stress and increases gene expression of antioxidant enzymes on rotenone-exposed rats. Neuropharmacology, 52 : 606-616.

Sedlak, J., Lindsay, R.H. 1968. Estimation of Total protein-bound, and nonprotein sulfhydryl groups in tissue with Ellman's reagent. Analytical Biochemistry, 25(1): 192-205.

Silva, B. A., Ferreres, F., Malva, J. O., Dias, A.C.P. 2005. Phytochemical and antioxidant characterization of Hypericum perforatum alcoholic extracts. Food Chemistry, 90: 157167.

Süntar, I.P., Akkol, E.K., Yılmazer, D., Baykal, T., Kırmızıbekmez, H., Alper, M., Yeşilada, E. 2010. Investigations on the in vivo wound healing potential of Hypericum perforatum L. Journal of Ethnopharmacology, 127: 468477.

Zheng, W., Wang, S. Y. 2001. Antioxidant activity and phenolic compounds in selected herbs. Journal of Agricultural and Food Chemistry, 49: 5165-5170.

Zou, Y., Lu, Y., Wei, D. 2004. Antioxidant Activity of a Flavonoid-Rich Extract of Hypericum perforatum L. in Vitro. Journal of Agricultural and Food Chemistry, 52(16): 5032-5039. 